\title{
NUEVAS REALIDADES EN EL TERCER SECTOR: LAS APORTACIONES JURÍDICO-ORGANIZATIVAS DE LAS FUNDACIONES CÍVICAS
}

\author{
POR \\ Julio JIMÉNEZ ESCOBAR ${ }^{1}$
}

\section{RESUMEN}

Las fundaciones cívicas constituyen una realidad incipiente en Europa aunque sus orígenes se remontan a comienzos del siglo XX. En España sin embargo, hasta fechas muy recientes, no empiezan a identificarse organizaciones que respondan a las características propias de este tipo de fundaciones.

El propósito de este trabajo es, en primer lugar, sistematizar los elementos configuradores específicos a nivel organizativo -finalidad, recursos, actividades, procesos y estructuras de gobierno- que subyacen en esta fórmula peculiar del Tercer Sector, exponiendo cómo se manifiestan a través de algunos ejemplos de buenas prácticas presentes en la realidad española. Esta sistematización sirve de base, en segundo lugar, para proponer una definición de fundación cívica, reflexionar sobre la pertinencia del término escogido para denominarlas y resaltar sus principales ventajas, aportaciones y novedades respecto a otras formas jurídicas alternativas -como las fundaciones clásicas y las asociaciones-, lo que las lleva a convertirse en un fenómeno de innovación social organizativa.

Por último se trazan las líneas maestras del encaje de este tipo de entidades en el ordenamiento jurídico español y se ponen de manifiesto algunas de las dificultades y desajustes normativos que pueden plantearse cuando la regulación vigente, fundamentalmente la de naturaleza tributaria, no tiene en cuenta de forma adecuada las particularidades de este tipo de entidades.

\footnotetext{
${ }^{1}$ Facultad de Ciencias Económicas y Empresariales (ETEA). Universidad de Córdoba. Dirección de correo electrónico:jjimenez@etea.com
}

REVESCO No 110 - Primer Cuatrimestre 2013 - ISSN: 1885-8031 - www.ucm.es/info/revesco

http://dx.doi.org/10.5209/rev REVE.2013.v110.41441

Fecha de recepción: 08/03/2012

Fecha de aceptación: 27/03/2012 
Palabras clave: Fundaciones cívicas, arquitectura organizativa, ventajas organizativas, innovación social, régimen jurídico, régimen fiscal.

Claves Econlit: K340, K390, L310, M140

\title{
NEW REALITIES IN THE THIRD SECTOR: THE LEGAL AND ORGANISATIONAL CONTRIBUTIONS OF COMMUNITY FOUNDATIONS
}

\begin{abstract}
Community Foundations are an emerging reality in Europe, although their origins date back to the early twentieth century. In Spain, however, until very recently there has been no awareness about organisations that answer to the characteristics of this type of foundation.

The purpose of this paper is, first of all, to systematize their specific distinguishing elements at organisational level, and the resources, activities, processes and governance structures that underlie this particular formula in the Third Sector, explaining how they manifest themselves through some present-day examples of good practice in the Spanish scenario. This systematization provides a basis, secondly, for proposing a definition for community foundations, reflecting on the relevance of the term chosen to designate and highlight their key advantages, contributions and innovations compared to other alternative legal forms (such as classical foundations and associations) which is leading them to become a phenomenon in social organisational innovation.
\end{abstract}

Finally we outline the intricacies of this type of entity within the Spanish legal system and highlight some of the difficulties and regulatory glitches that could arise if the current regulation, primarily concerned with taxes, does not adequately take into account the characteristics of such entities.

Keywords: Community Foundations, organisational architecture, organisational advantages, social innovation, legal, taxation. 


\section{LA REALIDAD DE LAS FUNDACIONES CÍVICAS EN EL MUNDO}

Un sistema organizativo precisa para su supervivencia de un propósito que sea viable. De igual modo todo propósito viable requiere de un sistema organizativo adecuado. Las asociaciones y las fundaciones han sido formas tradicionales de institucionalización de la sociedad civil que habitualmente han canalizado intereses y objetivos insuficientemente considerados por las entidades públicas y privadas. Sin embargo existen ciertos espacios de la compleja realidad de la ciudadanía que no han sido adecuadamente considerados e incorporados en las formas jurídicas más frecuentes en el Tercer Sector ${ }^{2}$ y la Economía Social $^{3}$.

Sin menoscabo del desarrollo e impacto que este tipo de formas jurídicas han tenido en la sociedad española y europea en las últimas décadas, podría apuntarse que en la formas asociativas se dan, en muchos casos, ciertas dificultades de gobierno y escasos recursos para la acción, lo que contrasta con la eficacia organizativa, pero excesiva concentración de poder, que suele producirse, por razones obvias, en las realidades fundacionales clásicas. Por ello resultan de gran interés las nuevas fórmulas que permiten captar recursos con autonomía de los poderes públicos, ejercer un gobierno eficaz y conectar con una base social lo más amplia posible. De esta manera surgen las fundaciones cívicas como nuevas formas de compromiso ciudadano, insuficientemente conocidas en España.

\footnotetext{
${ }^{2}$ La denominación de Tercer Sector fue empleada originariamente por Levitt (1973, pp. 48-49), designándose con ella a un conjunto complejo y heterogéneo de entidades que suelen definirse por exclusión: no son públicas, pero tampoco tienen fines lucrativos (Cabra de Luna, 1998, p. 24). En Europa también se utiliza el término "para describir un sector situado entre el sector público y el sector capitalista que se identifica con el concepto de economía social” (Monzón, 2006, p. 12). Parece ser que fue Jacques Delors quien comenzó a utilizarla en este sentido en unos cursos impartidos en la Universidad Paris-Dauphine (Jeantet, 2006).

Sin entrar ahora en consideraciones terminológicas y conceptuales, que excederían de las pretensiones de este trabajo, lo que sí resulta claro es que el término se viene utilizando en los últimos años en la legislación española para referirse de forma directa o indirecta, además de a otras entidades, a las fundaciones y asociaciones. Así se hace, entre otra normativa, en la Ley 49/2002, de 23 de diciembre, de régimen fiscal de las entidades sin fines lucrativos y de los incentivos fiscales al mecenazgo ("La importancia alcanzada en los últimos años por el denominado ‘tercer sector"”, primer párrafo de la Exposición de Motivos) o en la Ley 39/2006, de 14 de diciembre, de Promoción de la Autonomía Personal y Atención a las personas en situación de dependencia. En esta Ley el término se usa con frecuencia, hasta el punto de que el legislador lo ha definido en el artículo 2.8: " $A$ efectos de la presente, se entiende por" Tercer sector "las organizaciones de carácter privado surgidas de la iniciativa ciudadana o social, bajo diferentes modalidades que responden a criterios de solidaridad, con fines de interés general y ausencia de ánimo de lucro, que impulsan el reconocimiento y el ejercicio de los derechos sociales". Otras normas de rango legal que utilizan también el término son la Ley 16/2003, de 28 de mayo, de cohesión y calidad del Sistema Nacional de Salud (artículo 68.3) y la reciente Ley 2/2011, de 4 de marzo, de Economía Sostenible (disposición adicional vigésima).

${ }^{3}$ En España, el artículo 5.1 de la reciente Ley 5/2011, de 29 de marzo, de Economía Social, considera entre las entidades integrantes de la Economía Social a las fundaciones y asociaciones que lleven a cabo actividades económicas.
} 
A pesar de este escaso conocimiento y desarrollo en nuestro país, las fundaciones cívicas son un movimiento con presencia en todos los continentes. En el año 2000 había 905 fundaciones cívicas en el mundo; diez años después esa cantidad casi se había doblado y pasaron a ser 1680. En los años 2008 y 2009 se crearon 280 fundaciones cívicas. La mayoría de este crecimiento se produjo en Europa, donde la proliferación de estas fundaciones ha sido espectacular: se ha pasado de 103 en 2000 a 631 en 2010. El país con mayor crecimiento ha sido Alemania, pasando de 10 en el año 2000 a 240 en $2010^{4}$. También las fundaciones cívicas han aumentado en América del Norte, de 700 en 2000 a 880 en 2010, si bien el auge se produjo sobre todo entre 2000 y 2003. En otros continentes la cifra se ha mantenido por debajo de 100 fundaciones cívicas en toda la década, aunque parece que están creciendo en África y Asia. Estados Unidos es el país donde las fundaciones cívicas tienen los activos mayores, diecisiete veces más que los activos del siguiente país en la lista (Canadá). En el resto de países las fundaciones cívicas tienden a ser pequeñas, con poco personal y activos modestos ${ }^{5}$.

En España las fundaciones cívicas no nacieron con conciencia de su identidad, sino que se trata de unas entidades que por presentar una serie de características específicas han sido identificadas con posterioridad como fundaciones cívicas, sobre todo por el impulso de la Fundación Bertelsmann ${ }^{6}$. En el momento actual son las ocho siguientes: la Fundació Tot Raval, en la ciudad de Barcelona; la Fundació Ciutat de Valls, provincia de Tarragona; la

\footnotetext{
${ }^{4}$ En 1996 la Bertelsmann Stiftung inició el movimiento de fundaciones cívicas en Alemania. Con su constante ayuda e impulso se han creado muchísimas de estas fundaciones en ciudades grandes y pequeñas de todo el país. La Bertelsmann Stiftung también ha sido una de las principales promotoras de fundaciones cívicas en toda Europa, con la creación de la Red Transatlántica de Fundaciones Cívicas en 1999.

${ }^{5}$ Datos extraídos de 2010 Global Status Report on community foundations (Executive Summary), de WINGS. WINGS se formó en el otoño de 1999 al fusionarse una red de organizaciones de apoyo a fundaciones comunitarias y la Asamblea Internacional de Asociaciones al Servicio de Donantes (International Meeting of Associations Serving Grantmakers. El acrónimo es IMAG). WINGS es una red internacional de asociaciones y organizaciones de ayuda a donantes, con una sección formada por un grupo especial de entidades que apoyan a las fundaciones cívicas (WINGS-CF).

${ }^{6}$ En 2006 la Fundación Bertelsmann decidió asumir también el reto de promover el desarrollo de fundaciones cívicas en España. A través de su Centro de Competencias para Fundaciones Cívicas ofrece asesoramiento estratégico a las entidades que quieren convertirse en fundaciones cívicas, a las personas que quieren crearlas e incluso a las fundaciones cívicas que ya están en pleno funcionamiento. El objetivo de este Centro es apoyar su creación, profesionalizar el trabajo de las fundaciones ya existentes y fomentar el intercambio de experiencias y el aprendizaje entre las instituciones españolas. Esta entidad también concede en España la certificación: se inicia un proceso de análisis para dilucidar cuál es el punto de partida de la institución y evaluar qué requisitos le faltan para convertirse en fundación cívica. Tras este proceso, si se cumplen los requisitos, se hace entrega a la fundación del sello Fundación Cívica.

Agradezco a la Fundación Bertelsmann y especialmente a Mercedes Mosquera, directora de su Centro de Competencias para Fundaciones Cívicas, la colaboración prestada en la elaboración de este trabajo.
} 
Fundación Maimona, provincia de Badajoz: la Fundación Novessendes ${ }^{7}$, en Betxí, provincia de Castellón; la Fundació Horta Sud, en Torrent, provincia de Valencia; la Fundación Cáceres Capital; la Fundació d’ Entitats Culturals, en Badia del Valles, provincia de Barcelona, y la Fundación Ciudad de Sigüenza, en la provincia de Guadalajara. Estas entidades y otras fundaciones forman parte de la Red Española de Fundaciones Cívicas ${ }^{8}$.

Nuestro propósito en este trabajo es sistematizar la lógica organizativa singular que subyace en esta fórmula peculiar del Tercer Sector a partir de las características que, identificadas por WINGS, se admiten internacionalmente que están presentes en las fundaciones cívicas. Expondremos también algunos ejemplos de buenas prácticas presentes en los diversos casos disponibles en la realidad española, pues permitirán captar cómo se vienen concretando aquellos caracteres en la incipiente realidad española. La sistematización de la especificidad organizativa de estas fundaciones nos servirá de base para explicitar sus novedades organizativas más significativas, proponer una definición de fundación cívica y reflexionar sobre la pertinencia del término escogido para denominarlas, así como para identificar sus principales aportaciones y ventajas organizativas. Terminaremos analizando el encaje de este tipo de entidades en el ordenamiento jurídico-español.

\section{CARACTERÍSTICAS DE LAS FUNDACIONES CÍVICAS}

Aunque lógicamente no hay dos fundaciones cívicas exactamente iguales, pues la tradición, la historia y la cultura local configuran de forma particular a cada entidad, sí se puede afirmar que las fundaciones cívicas comparten un conjunto de características, aunque cada fundación pueda otorgar más énfasis a unas que a otras. Este conjunto de características que destacaremos inmediatamente están en muchas organizaciones del Tercer Sector, pero cuando están presentes todas ellas en una misma entidad es cuando nos encontramos ante una fundación cívica (VV.AA, 2011, p. 22).

En el contexto internacional se suele considerar que estas características son las que aparecen en el informe The Growts of Community Foundations Around the World. An

\footnotetext{
${ }^{7}$ Hasta 2009 fue una fundación de empresa familiar. Sin embargo la Fundación decidió transformarse en una fundación cívica. Es el primer caso de transformación de este tipo conocido en el mundo, para lo que se cambiaron los miembros del patronato para abrirse a la comunidad, se diversificó la captación de fondos y los donantes, etc.

${ }^{8} \mathrm{La}$ Red está formada por fundaciones cívicas certificadas, pero también por fundaciones que, sin cumplir todavía los requisitos necesarios para ser calificadas como tales, quieren dar los pasos necesarios para llegar a serlo. En esta situación se encuentran la Fundación Ciudad Rodrigo 2006 (Salamanca), la Fundación Igualdad Ciudadana (Cáceres) y la Fundación Galicia Sustentable.
} 
examination of the vitally of the community foundation movement, Council on Foundations (Sacks, 2000; pp. 2 y 3) ${ }^{9}$. Según este informe las fundaciones cívicas se caracterizan por los siguientes rasgos:

1. Tienen por finalidad mejorar la calidad de vida en un área geográfica determinada.

2. Son independientes del control o la influencia de otras organizaciones, gobiernos o donantes.

3. Están regidas por un órgano constituido por ciudadanos que reflejan ampliamente las comunidades a las que sirven.

4. Otorgan donaciones a otros grupos de carácter no lucrativo para abordar toda una serie necesidades emergentes y cambiantes en la comunidad.

5. Aspiran a establecer unos recursos permanentes para la comunidad, casi siempre a través de la creación de fondos aportados por un amplio abanico de donantes, que incluye a ciudadanos, corporaciones y gobiernos locales, y otras organizaciones no lucrativas y empresas.

6. Prestan servicios a la medida de los intereses y capacidad de aportación de los donantes.

7. Ayudan a los donantes a lograr sus metas filantrópicas y de beneficencia.

8. Participan en actividades asociativas y de liderazgo de la comunidad y actúan como catalizadores, convocantes, colaboradores y coordinadores para resolver problemas e impulsar soluciones en asuntos importantes de la comunidad.

9. Cuentan con unas políticas y prácticas abiertas y transparentes en todos los aspectos de su actividad.

\footnotetext{
9 Este informe del año 2000, elaborado por Eleanor W. Sacks, sobre la formación de las fundaciones comunitarias (denominadas "cívicas" en España y en Alemania) en todo el mundo, es un proyecto conjunto de Programas del Consejo de Fundaciones (Programs of the Council on Foundations) y de Iniciativas Mundiales de Apoyo a Donantes - Fundaciones Comunitarias (Worldwide Initiatives for Grantmaker Support-Community Foundations) (WINGS-CF).
} 
10. Responden ante la comunidad informando regularmente a la población en general sobre sus objetivos, actividades y situación financiera.

Considerando estas características puede vislumbrarse una lógica organizativa específica con respecto a sus fines, recursos, actuaciones, estructura y procesos ${ }^{10}$. De ello y de la forma en que estos elementos se han ido concretando en las fundaciones cívicas españolas nos ocupamos en el siguiente epígrafe.

\section{LA ARQUITECTURA ORGANIZATIVA DE LAS FUNDACIONES CÍVICAS}

\subsection{Fines genéricos enfocados localmente}

Las fundaciones cívicas tratan de mejorar la calidad de vida en un área geográfica determinada. Se trata por ello de unos fines muy genéricos (abiertos a lo que necesite la comunidad en cada momento) pero que a la vez poseen un marco de delimitación para su concreción muy definido (su ámbito geográfico local). Este ámbito local puede ser diverso (un barrio, una ciudad, una comarca o una provincia), pero suele presentar unas características específicas propias. Esta finalidad tendencialmente abierta a una amplia gama de actividades constituye una singularidad en el elenco de las entidades del Tercer Sector ${ }^{11}$.

La plasmación de estos rasgos en la realidad española se aprecia claramente en ejemplos como los de las fundaciones Novessendes y Tot Raval. En el primer caso (St. John, 2009c) se trata de una fundación local que pretende contribuir al fomento de la responsabilidad social, al compromiso cívico en favor de la comunidad y a la resolución de sus problemas a través del apoyo a iniciativas de personas y organizaciones ciudadanas ${ }^{12}$. En un sentido similar, pero con elementos específicos, podríamos referirnos a la Fundación Tot Raval (St. John, 2007) y a su indiscutible implicación en la subsanación de los problemas que

\footnotetext{
${ }^{10}$ Sobre los aspectos generalmente relevantes en la arquitectura organizativa de las entidades sin fines lucrativos puede verse Jiménez y Morales (2006, pp. 26-41).

${ }^{11}$ En las entidades no lucrativas el carácter prevalente del fin o la misión (entidades misioneras) comporta normalmente que tengan menos alternativas de actuación que las entidades lucrativas, ya que éstas al pretender como fin último obtener una ganancia económica que será objeto de un ulterior reparto entre sus miembros, cuentan con una considerable libertad de actuación en la elección de los medios para alcanzar tal objetivo: pueden diversificar enormemente las actividades a realizar, abandonar sin muchos problemas aquellas que no resulten rentables, adaptarse a las preferencias y gustos del mercado en cada momento, etc. (Jiménez y Morales, 2008, p. 91). Por el contrario, la importancia del fin o la misión en las entidades sin fines lucrativas establece importantes limitaciones en relación con las actividades a emprender (HERRERA GómEZ, 1998, p 185), pues deben ser siempre coherentes con los fines de las entidad e, incluso, con respecto a la forma de llevarlas a cabo. 12 http://www.novessendes.org. en el menú de la derecha "Quiénes somos".
} 
afectan al barrio barcelonés del Raval ${ }^{13}$. Los Estatutos de esta Fundación señalan que el objeto de la misma es, entre otros, "La promoción, en el ámbito del Raval de Barcelona, de todo tipo de proyectos y actividades, orientados a favorecer el pleno desarrollo del Raval en los órdenes social, económico y cultural” (artículo 5).

\subsection{Recursos preponderantemente locales y variados en su orígen y naturaleza}

En las fundaciones cívicas los medios necesarios para cumplir este fin social-territorial están comprometidos y enraizados igualmente en la comunidad, en la ciudadanía organizada en su sentido más amplio. Desde estos principios tratan de crear o asegurar un flujo permanente de recursos de la comunidad para la propia comunidad. En este sentido se esfuerzan por canalizar, coordinar y articular la ayuda de colaboradores de todo tipo, tanto de los que quieren hacerlo con dinero y bienes (donantes), como de quienes quieren aportar, mediante el voluntariado o su participación altruista en los órganos de gobierno de la entidad, su tiempo, conocimiento, redes de relaciones y contactos, etc.

En la vertiente de los recursos económicos y patrimoniales resulta característico, como ya se ha señalado, el interés de las fundaciones cívicas por crear fondos aportados por un amplio abanico de donantes, que incluye a ciudadanos, empresas, corporaciones, gobiernos locales, fundaciones y otras entidades no lucrativas. A esto coadyuva sin duda otro de los rasgos característicos de las fundaciones cívicas: su deseo de prestar servicios a la medida de los intereses y la capacidad de aportación de los donantes, ayudando a que éstos logren sus metas filantrópicas y de beneficencia. En opinión de McInnes (2009, p. 105) es esta tendencia de las fundaciones a incrementar la implicación de los donantes lo que más ha contribuido a su extraordinario crecimiento en los últimos años. Cuando las fundaciones cívicas captan recursos financieros de muchos donantes distintos están contribuyendo de forma importante a "la democratización de la filantropía" (deCoricy Hero y Walkenhorst, 2009, p. 20) y del “compromiso filantrópico" (B. Mohn, 2006, p. 94).

Un caso que ilustra este rasgo de las fundaciones cívicas en la realidad española lo

\footnotetext{
${ }^{13}$ El Raval es un barrio de la ciudad de Barcelona que se encuentra en el distrito de Ciutat Vella (Casco Antiguo). Tiene una población de 47.064 habitantes e históricamente ha sido el barrio de Barcelona que ha acogido a los nuevos inmigrantes. Hoy más de la mitad de los residentes son inmigrantes. Según la Guía Frommer de Barcelona, "recientemente se ha dicho del Raval que es el barrio más multicultural de Europa, lo que se puede comprobar fácilmente con un rápido recorrido por su laberinto de calles, donde conviven comerciantes paquistaníes de productos textiles y vendedores de especias sudamericanos con establecimientos tradicionales que venden bacalao en salazón y vino del lugar. El adhan (la llamada de los musulmanes a la oración) se emite desde mezquitas ubicadas en locales situados a pie de calle junto a bares de estilo neohippie, escuelas de yoga y galerías de arte contemporáneo" (St. John, 2007).
}

REVESCO No 110 - Primer Cuatrimestre 2013 - ISSN: 1885-8031 - www.ucm.es/info/revesco 
encontramos en la Fundación Tot Raval, que prevé en sus estatutos la posibilidad de crear fondos especiales destinados al cumplimiento de las finalidades, siempre dentro de los fines comprendidos en el objeto de la Fundación, acordadas con los aportantes de bienes o derechos $^{14}$. También la Fundació Ciutat de Valls ofrece a ciudadanos y empresas la posibilidad de crear fondos nominales con fines filantrópicos específicos, garantizando el esmerado reparto de dichos fondos de conformidad con la intención del donante.

\subsection{Actividades y servicios de colaboración}

Las fundaciones cívicas, para ser consideradas como tales, tienen que conceder donativos y ayudas económicas a otros grupos de carácter no lucrativo para que hagan frente a toda una serie de necesidades cambiantes de la comunidad. Con ello canalizan los recursos económicos obtenidos de diversas fuentes apoyando las iniciativas y proyectos de otros. De esta forma crean una especie de capital filantrópico, que unas veces utilizan ellas directamente y otras ponen al servicio de otras entidades que trabajan en actividades relacionadas con los fines de la propia fundación cívica. En España podemos destacar el caso de Tot Raval (St. John, 2007), que ayuda a desarrollar proyectos mediante apoyo económico tradicional, pero también con una serie de medios no tan habituales, desempeñando un papel pionero que se podría calificar de "intermediario" de la comunidad. Una forma de ayudar a su comunidad es, por ejemplo, contactar con las autoridades públicas locales para que sufraguen el salario de un empleado para la asociación u ONG que presenta un proyecto a la fundación.

En ocasiones el apoyo se concede a entidades lucrativas (empresas) para contribuir al desarrollo local, como sucedió en el caso de la Fundación Maimona (St. John, 2009a). Esta entidad constituyó un fondo para la concesión de préstamos a través de un modelo de capitalriesgo orientado a la creación de empresas para favorecer así el desarrollo del territorio ${ }^{15}$.

\footnotetext{
${ }^{14}$ La constitución de estos fondos especiales debe realizarse en escritura pública, y en el acta de constitución de los mismos se tienen que hacer constar la denominación del fondo, los fines para los que se constituye, los bienes y derechos destinados a financiar el fondo y la forma en que se hace o se hará la aportación, la duración del fondo o si es indefinida, las causas especiales de extinción, y el destino del patrimonio del fondo, salvo que se haya convenido un término especial de duración (artículo 27 de los Estatutos).

${ }^{15}$ El patronato creó un fondo para préstamos de un millón de euros para la expansión o creación de empresas en la comunidad. Hasta el 2007 se efectuaron préstamos por valor de 1.127.245 euros (bastante más que el importe inicial del fondo, lo que refleja la devolución de préstamos reciclados, es decir, devueltos y reinvertidos en otro proyecto) a 48 empresas nuevas y en expansión. Sin embargo, los recursos financieros de la fundación sólo representan una pequeña parte del conjunto. Mediante un modelo de capital riesgo, Maimona complementó su compromiso financiero con experiencia de gestión, ayudando a las empresas al desarrollo de sólidos planes de negocio. Además, cada inyección financiera (en su mayor parte en forma de préstamos, aunque en ocasiones en la de inversiones de capital) ha movilizado recursos del empresario o de la empresaria en cuestión, así como de otras instituciones financieras.
} 
Pero las acciones de las fundaciones cívicas no se circunscriben a la mera redistribución de recursos monetarios, sino que también participan en toda una serie de actividades asociativas y de liderazgo, actuando como catalizadores, convocantes, colaboradores y coordinadores con el fin de resolver problemas e impulsar soluciones en asuntos importantes para la comunidad. Con ello las fundaciones cívicas están contribuyendo a la creación de capital social, lo que fortalece el tejido esencial de sus comunidades (Walkenhorst, 2001).

En el caso de la Fundación Tot Raval sus propios Estatutos, cuando delimitan el objeto de la Fundación, señalan que "se trata, en general, de un objeto amplio, abierto a dar apoyo e integrar el trabajo de otras fundaciones, entidades y agentes con los que la Fundación comparta finalidades y que tengan también como objeto la mejora cultural, social, económica y comercial del Raval, procurando mantener un equilibrio armónico entre viejos y nuevos valores del Raval"16. Al referirse a las finalidades de la Fundación (art. 6 Estatutos), se señala, entre otros fines, el de "Dar impulso y coordinar iniciativas de toda clase surgidas del rico entramado asociativo, social y cultural del Raval”.

Otro ejemplo similar de esta actitud colaborativa lo constituye la Fundación Horta Sud, que realiza convocatorias de ayudas para proyectos interasociativos.

\subsection{Estructuras de gobierno independientes, nítidas y significativas}

Las fundaciones cívicas intentan preservar su independencia organizativa y de gestión y no verse sometidas al control o la influencia de otras organizaciones, gobiernos o donantes. Por su forma jurídica, el gobierno de la entidad corresponde al patronato, que por imperativos de la propia legislación sustantiva cuenta con amplias facultades y competencias, debiendo adoptar las decisiones más relevantes. Se trata de una estructura de gobierno "nítida"claramente definida- y centralizada. Esto es característico de toda fundación y debe garantizar su autonomía e independencia respecto a sujetos o entidades ajenos a la organización (autonomía ad extra).

\footnotetext{
${ }^{16}$ Artículo 5 de los Estatutos. En este artículo se establece que el objeto de la Fundación está constituido, entre otros, por "el soporte a todas aquellas iniciativas que, surgidas de los agentes y entidades del Raval, requieren un impulso para poder realizarse en condiciones óptimas", por el soporte "a aquellas iniciativas que aún siendo promovidas por entidades o agentes no residentes en el Raval, tengan como destino el Raval y sean coincidentes con el objeto y finalidades de la fundación”, y por "la realización, a través de las diferentes entidades del Raval o por iniciativa propia, de exposiciones, festivales, conciertos, etc. que tienden a favorecer el conocimiento de la riqueza cultural del Raval y de las instituciones y entidades de carácter cultural y artístico".
} 
En las fundaciones cívicas concurre también otro aspecto que puede generar ad intra de la organización ciertos equilibrios en el desempeño del poder (a través de su ejercicio en el patronato), y con ello evitar que pueda primar, en demasía, la visión o perspectiva de un sujeto o grupo de personas. El hecho de que en las fundaciones cívicas el patronato esté constituido por ciudadanos que reflejan ampliamente a la comunidad a la que sirve la entidad, otorga a cada uno de ellos, a priori, una significación y un papel importante en el órgano colegiado. El patronato de una fundación cívica debe ser significativo, en las dos acepciones del término, en relación con la comunidad en la que actúa la Fundación. Por un lado, debe reflejar a la propia comunidad, es decir, ser revelador o representativo de aquélla (en el sentido de que la muestra o da a conocer). Pero, precisamente por ser reflejo de esa comunidad, puede ser muy eficaz para detectar, de una forma plural y desde distintas perspectivas, los problemas que afectan realmente a esa colectividad y para proponer, también desde diversos enfoques, las soluciones que se consideran más viables y pertinentes, constituyendo por ello un órgano relevante e importante (segunda acepción del término significativo).

Esta gestión de la pluralidad en el ámbito interno es muy importante. No sólo porque enriquece las fuentes de información y los criterios de decisión, sino porque constituye un aprendizaje organizativo indispensable para la colaboración con otros sujetos y entidades ajenos a la organización, lo que permite la generación del capital social al que nos hemos referido en el apartado anterior. La cultura de la cooperación y la colaboración, desde la pluralidad y la diversidad, debe ser por ello algo característico de las fundaciones cívicas. Las formas utilizadas para conseguir o lograr esta representatividad son diversas.

En el caso de la Fundació Ciutat de Valls (St. John, 2009b) existe un patronato plural nutrido de instituciones culturales, sanitarias, del mundo de la empresa, la banca y las profesiones liberales. Pero además esta fundación cuenta con un Consejo Consultivo, como órgano asesor, compuesto por los antiguos alcaldes e individuos nombrados por instituciones representativas como el Consejo Comarcal, el arciprestazgo del Alt Camp y otros designados por la propia fundación, garantizando que son reflejo de la comunidad y receptivos a la misma $^{17}$.

En la Fundación Maimona (St. John, 2009a) el patronato -compuesto por siete

\footnotetext{
${ }^{17}$ El Consejo Consultivo actual, además de las personalidades citadas, está formado por personas vinculadas al Gobierno de la Generalitat de Cataluña, la universidad, la banca, el periodismo y la empresa.
} 
miembros- también pretende reflejar a la comunidad a través de sus componentes: el fundador, dos personajes públicos (de orientaciones ideológicas diferentes), un profesor, un abogado, un banquero y un funcionario universitario.

Finalmente, en la Fundación Tot Raval se ha creado una estructura de gobierno original y muy "representativa" (St. John, 2007). El patronato está constituido por patronos vitalicios, un máximo de quince formado por las personas físicas o jurídicas designadas en la escritura fundacional y las llamadas posteriormente con tal condición ${ }^{18}$, y por patronos temporales, un máximo de sesenta, nombrados por el patronato en pleno, que ejercen su cargo por períodos de cuatro años. Estos patronos temporales, constituidos tanto por personas físicas como por instituciones, son un amplio reflejo de la comunidad en la que opera la Fundación Tot Raval. Una Junta de Gobierno, integrada por un máximo de quince miembros nombrados por períodos de cuatro años, constituye el órgano ejecutivo responsable de la supervisión cotidiana de las actividades (artículos 17 y 18 de los Estatutos).

Finalmente, el interés de las fundaciones cívicas por crear un fondo que se nutre de un amplio abanico de donantes, al que ya hemos aludido con anterioridad, otorga un dinamismo singular que favorece la captación de recursos para la acción procedentes de fuentes muy diversas, y no sólo a partir de los recursos iniciales, sus frutos o de un grupo de donantes reducido. Con esto se gana en autonomía e independencia a la hora de identificar y abordar las nuevas necesidades.

\subsection{Procesos transparentes y participativos}

Las fundaciones cívicas desarrollan unas políticas y prácticas abiertas, participativas y transparentes en relación con todos los aspectos de su actividad. Por ejemplo, el proceso de concesión de las ayudas de Tot Raval (St. John, 2007) empieza con tres "comisiones de trabajo" voluntarias que son representativas de tres ámbitos prioritarios de la vida de la comunidad: el social, el económico y el cultural ${ }^{19}$. Las comisiones de trabajo "son el espacio de análisis de las necesidades e intereses del barrio donde se proponen, deciden y diseñan, en mayor o menor medida, los proyectos a presentar a la Junta (de gobierno) para ser impulsados". Estas comisiones se encuentran formadas por organizaciones y personas que son

\footnotetext{
${ }^{18}$ Estos patronos vitalicios tienen ya un carácter muy representativo, pues lo forman una serie de empresarios y asociaciones culturales y sociales del barrio que constituyen el núcleo fundador de la entidad. La función de estos patronos vitalicios es asegurar la continuidad de los trabajos de la Fundación (artículo 11 de los Estatutos).

${ }^{19}$ En el artículo 23 de los Estatutos de la Fundación Tot Raval se contemplan tres áreas de gestión en la Fundación: la social y humana, la cultural y lúdica, y la económica y cultural.
} 
miembros del Patronato, pero también por otras que tienen interés y capacidad para participar e implicarse $\mathrm{e}^{20}$.

Otros ejemplos de participación en la Fundación Tot Raval lo constituyen la existencia de los Consejos Asesores y la Asamblea de Protectores. Los Consejos Asesores están integrados por un mínimo de tres y un máximo de quince miembros, que no tienen que ser patronos, compuestos por técnicos especializados en las materias específicas de cada Consejo Asesor. Estos Consejos tienen “como objeto informar, proponer y evaluar las actividades técnicas-científicas, docentes y diseño de los programas de la Fundación, en las distintas áreas de actividad, así como elaborar informes y asesoramientos, con carácter no vinculante" (artículo 26 de los Estatutos). Por otro lado, la Asamblea de Protectores de la Fundación Tot Raval tiene derecho a ser informada de las actividades, planes y programas de actuación de la Fundación, del destino y gestión económica de sus aportaciones, participar en las actividades programadas y realizar propuestas para incluirlas en el programa de actuación de la Fundación (artículo 29). Es importante destacar que en los Estatutos se establece que se "invitará especialmente a formar parte del grupo de protectores y amigos de la Fundación a las distintas Administraciones, el mundo empresarial, el movimiento asociativo, el voluntariado y, en general todas aquellas personas físicas y jurídicas, públicas y privadas interesadas en la tarea y objetivos que se pretendan desarrollar desde la Fundación” $\left(\right.$ artículo 28.5) ${ }^{21}$.

En esta lógica de participación y transparencia las fundaciones cívicas también rinden cuentas ante la comunidad e informan regularmente al público en general sobre sus objetivos, sus actividades y su situación financiera. La cercanía y alto nivel de inserción en la realidad

\footnotetext{
${ }^{20}$ La Fundación da prioridad a proyectos: (1) que aporten un mayor conocimiento sobre el barrio; (2) que impliquen al máximo número de colectivos, organizaciones y entidades del barrio, vista la diversidad de gentes y grupos; (3) que comprometan prioritariamente a las entidades "miembros" de la Fundación, así como también a otras entidades que no formen parte de la misma, en la coordinación y en la corresponsabilización de los proyectos; (4) que incidan en las necesidades prioritarias del barrio; (5) que busquen la crítica social, económica y cultural, y propongan nuevas líneas de actuación para revalorizar el barrio; (6) que busquen espacios de diálogo e interacción entre los diversos valores culturales del barrio; (7) que planteen formatos no convencionales, de carácter novedoso, para llegar al público. Las comisiones suelen recomendar los proyectos a la Junta de Gobierno si la fundación puede asumirlos económicamente o si es fácil encontrar recursos para los mismos.

${ }^{21}$ También tienen la consideración de amigos y protectores de la Fundación los fundadores relacionados en la carta fundacional; las entidades que, por razón de la convergencia de objetivos, consideren de interés participar en la misma; las personas eminentes designadas por el Patronato en atención a sus méritos en el campo de la Fundación; las personas físicas o jurídicas de naturaleza pública y privada que contribuyan a mantener o aumentar el patrimonio de la Fundación, mediante iniciativas de patrocinio, mecenazgo, voluntariado, y aportaciones para la constitución de fondos especiales destinados al cumplimiento de determinadas finalidades (artículo 28 de los Estatutos).
} 
local de los diversos agentes que colaboran con la entidad comporta que las fundaciones cívicas desarrollen su actividad con unos niveles de transparencia muy elevados, pues los colaboradores tienen una percepción inmediata de los logros obtenidos con las actividades de la fundación.

\section{UN MODELO ORGANIZATIVO DE NATURALEZA HÍBRIDA}

\subsection{La especificidad de las fundaciones cívicas}

Tras la sistematización realizada de los rasgos configuradores del diseño organizativo que representan las fundaciones cívicas, conviene poner de manifiesto qué implica, como singularidad, añadir el término cívico al concepto genérico de fundación. Partimos para ello de las características básicas que suelen atribuirse a la fundación, en tanto que persona jurídica de naturaleza privada. En toda fundación aparece un elemento organizativo (normalmente especificado en los estatutos), un elemento patrimonial (concretado en la dotación inicial que aparece en la escritura fundacional) y un elemento teleológico (los fines de la entidad, que deben ser de interés general, y aparecen especificados en la propia escritura fundacional y en los estatutos). Podemos decir que a una estructura patrimonial (dotación inicial) y organizativa (tanto respecto a la estructura como a los procesos básicos) se la dota de personalidad jurídica para alcanzar unos fines de interés general. Desde esta perspectiva, cabría señalar que las fundaciones cívicas adquieren su singularidad como fundación por las siguientes notas:

a) En cuanto a sus fines, son genéricos y están enfocados a una comunidad local.

b) En cuanto a sus recursos, son de procedencia preponderantemente local, tendencialmente crecientes y de origen múltiple los patrimoniales, y de gran importancia y significación los personales.

Los recursos de naturaleza patrimonial son tendencialmente crecientes y de origen múltiple porque se pretende que no queden circunscritos a la dotación inicial y a los frutos o rentas derivados de la misma, sino que, a partir de donaciones de un amplio abanico de donantes (ciudadanos, corporaciones y gobiernos locales, y otras fundaciones y entidades no lucrativas), se quiere generar un fondo patrimonial permanente y sin restricciones. Son por ello fundaciones muy dinámicas en la captación de recursos y con mucha apertura hacia 
colaboraciones muy diversas, convirtiéndose en un cauce muy adecuado para canalizar la solidaridad y altruismo de donantes y voluntarios.

Asimismo, y en contraste con otros tipos de fundaciones, en las fundaciones cívicas los elementos personales cobran también una relevancia sustancial, hasta el punto de que si no aparecen difícilmente podría catalogarse como cívica a la fundación. La implicación e integración de determinados sujetos o colectivos con motivaciones altruistas se torna en algo esencial en la propia caracterización de la entidad, y ello, como veremos seguidamente, tanto en las estructuras de gobierno de las fundaciones cívicas como en su cultura organizativa y procesos.

c) En cuanto a la organización, la estructura de gobierno debe ser significativa y los procesos participativos, colaborativos y transparentes.

En el gobierno deben participar sujetos (patronos) que sean personas significativas, en el sentido ya comentado, de la comunidad en la que actúa la fundación. La cultura organizativa tiene que responder a dinámicas participativas y de colaboración para que la fundación cívica realmente pueda cumplir con sus objetivos (que constituyen un rasgo configurador) de ayudar a otros (colaborando económicamente con los proyectos de éstos) o de liderar y coordinar iniciativas de diversos agentes (actividades de liderazgo comunitario) en el ámbito local.

\subsection{Diferencias y semejanzas respecto a los modelos asociativos}

Por lo que respecta a las diferencias de las fundaciones cívicas con las formas asociativas resultan claras y derivan fundamentalmente de su naturaleza jurídica de fundación. $\mathrm{Al}$ ser tales, los fines deben ser de interés general ${ }^{22}$, lo que no acontece, necesariamente, en las asociaciones, pues éstas pueden tener fines de interés particular ${ }^{23}$, de ahí que, en el caso español, para que una asociación sea declarada de utilidad pública (lo que podemos considerar equivalente al interés general) se requiere de un complejo y exigente procedimiento administrativo que culmine con tal declaración ${ }^{24}$. De hecho muy pocas asociaciones en España son de utilidad pública. Por otro lado, y a diferencia de lo que ocurre en las

\footnotetext{
${ }^{22}$ Artículo 34.1 de la Constitución española.

${ }^{23}$ Artículo 5.1 Ley Orgánica 1/2002, de 22 de marzo, reguladora del Derecho de Asociación. El reconocimiento del Derecho de asociación no va ligado a la exigencia constitucional (artículo 22 Constitución) de que sus fines o actividades deban ser de interés general (Paniagua Zurera, 2011, p. 203).

${ }^{24}$ Sobre los requisitos y el procedimiento para obtener tal declaración y los derechos y deberes de las asociaciones de utilidad pública véase Paniagua Zurera (2006, p. 173-179).
} 
asociaciones, se debe contar con una cierta base patrimonial que se concreta en la dotación inicial. Finalmente, por tratarse de una fundación, el gobierno corresponde al patronato, que se dota conforme a los criterios que se han considerado más pertinentes en los estatutos de la fundación, gozándose por ello con una gran flexibilidad a la hora de determinar su composición. Patronato que conforme a la propia normativa legal tiene importantes competencias, pero también un claro régimen de responsabilidades, con lo que puede evitarse la complejidad que supone la toma de decisiones en órganos con muchos miembros (todos los asociados, en el caso de las asociaciones), en los que además las responsabilidades pueden tender a difuminarse.

El término cívicas, que acompaña al sustantivo fundación, aporta ciertos elementos más próximos a las formas asociativas, pues los elementos de naturaleza personal cobran una gran relevancia y significación, tanto en la estructura de gobierno (patronato) como en la cultura organizativa y los procesos, a partir de ciertas lógicas participativas y cooperativas propias de los modelos asociativos ${ }^{25}$. Su misión abierta, que debe ir concretándose según las necesidades de la comunidad por un órgano de gobierno que cuenta con personas significativas de dicha comunidad, lo aproxima también, en cierta medida, al diseño organizativo de las asociaciones, pues de alguna forma la base social tiene participación cuando se deciden las acciones a realizar para cumplir con los fines de la fundación. En las asociaciones esto se realiza a través de la asamblea de socios y en las fundaciones cívicas mediante un patronato que refleja a la propia comunidad al ser revelador o representativo de ella.

\section{UN CONCEPTO Y UNA DENOMINACIÓN PARA ESTE NOVEDOSO "DISEÑO" ORGANIZATIVO}

Teniendo en consideración los rasgos configuradores del diseño organizativo de las fundaciones cívicas podríamos definirlas como organizaciones solidarias que trabajan por el desarrollo y bienestar de una comunidad local, utilizando fundamentalmente recursos económicos y personales de la propia comunidad, y con una arquitectura organizativa caracterizada tanto por una estructura de gobierno nítida, centralizada y significativa como por unos procesos abiertos, participativos y transparentes.

\footnotetext{
${ }^{25}$ Como desde hace mucho tiempo viene señalando la doctrina (Sánchez de Frutos, 1965, p.884) es propio de los modelos asociativos "responder de modo natural a la idea de unión de fuerzas, mientras que las fundaciones responden a la idea de perpetuación de la voluntad humana".
} 
A raíz de esta realidad conceptual nos parece que la denominación más extendida internacionalmente, la de fundaciones comunitarias ${ }^{26}$, recoge en mayor medida los aspectos señalados en el párrafo anterior. Es lo comunitario lo que define y enmarca precisamente todos y cada uno de los rasgos de este concepto: para qué y en favor de quién se actúa, de dónde provienen fundamentalmente los recursos, lo que determina la significación en el órgano de gobierno, quién participa en los procesos y evalúa los resultados (transparencia). No obstante, la denominación de fundaciones cívicas (en el sentido de relativas a los ciudadanos) también resulta apropiada, pues parece que pone su enfásis en determinados elementos de naturaleza personal que las caracterizan, siendo precisamente estas características, que las aproximan a los rasgos de los modelos asociativos, las que hacen que estas entidades se configuren con una naturaleza híbrida. Estamos ante una fundación que injerta en su organización, a través de sus estatutos y unas formas de actuar que cristalizan en una determinada cultura organizativa, el carácter participativo típico de las asociaciones, con lo que mantiene las ventajas de las fundaciones y le suma virtualidades de las organizaciones asociativas.

Dependiendo de que se quiera poner el acento bien en lo que define y configura a la entidad en su integridad -la importancia del ámbito local para la configuración de todos los rasgos idiosincráticos de la fundación-, o bien en la singularidad organizativa de aquélla (fundación con presencia de importantes elementos o características de naturaleza personal), se optará por un término u otro. Nos parece que el término de fundación comunitaria resalta más el ámbito del que se nutre (toma los recursos) y en el que actúa la fundación: la comunidad local. Sin embargo, la denominación de fundación cívica pone el acento en el compromiso ciudadano. De ahí que se suela decir que las fundaciones cívicas son fundaciones de ciudadanos para ciudadanos.

\section{LAS PRINCIPALES VENTAJAS Y APORTACIONES DE ESTE DISEÑO ORGANIZATIVO HÍBRIDO}

La hibridación que se presenta en el diseño organizativo de las fundaciones cívicas produce una serie de virtualidades tanto para la organización como para el conjunto de entidades afines -el Tercer Sector -. Estas ventajas afectan fundamentalmente a la eficacia organizativa y las más significativas las exponemos a continuación. Las tres primeras derivan

\footnotetext{
${ }^{26}$ La denominación de fundaciones comunitarias es la que se emplea prácticamente en todos los países (Estados Unidos, Reino Unido, los países latinoamericanos, Italia, países del este europeo, etc.) salvo en España y Alemania en los que se viene utilizando el término de fundaciones cívicas.
} 
de la naturaleza fundacional de estas entidades, el resto son consecuencia de su aproximación a los caracteres propios de los modelos asociativos. Son las siguientes:

1. La forma jurídica de fundación facilita, desde el primer momento, y a diferencia de las asociaciones, la percepción de que se trata, indudablemente, de una entidad que persigue fines de interés general, lo que puede suponer un mayor reconocimiento social y jurídico. Esto contribuye, por un lado, a que la legislación suela otorgar un tratamiento fiscal beneficioso a la entidad ${ }^{27} \mathrm{y}$, por otro, a facilitar que existan colaboraciones altruistas con la entidad, a lo que también coadyuva la regulación fiscal incentivadora del mecenazgo. En el caso español esta normativa beneficiosa ${ }^{28}$ únicamente se aplica a las asociaciones que han sido declaradas de utilidad pública (Jiménez Escobar, 2006a, p. 196-215), y este reconocimiento no resulta fácil de lograr.

2. La necesidad de una dotación inicial en las fundaciones favorece que haya necesariamente unos recursos económicos mínimos de partida ${ }^{29}$. Esto permite comenzar a desarrollar, con cierta solvencia, las actividades propias de la fundación, lo que supone una indudable ventaja respecto a los modelos asociativos ${ }^{30}$.

3. La libertad y flexibilidad para configurar la composición del máximo órgano de gobierno, el patronato, conforme a los criterios que se consideren más pertinentes en lo

\footnotetext{
27 Existe un consenso bastante generalizado entre la doctrina tributaria en que la concurrencia de dos caracteres en una entidad, el no tener ánimo de lucro y la realización de actividades de interés general, justifica y fundamenta el reconocimiento de una serie de beneficios fiscales para las mismas (Jiménez Escobar, $2006 \mathrm{~b}, \mathrm{p}$. 229).

${ }^{28}$ La Ley 49/2002, de régimen fiscal de las entidades sin fines lucrativos y de los incentivos fiscales al mecenazgo regula un elenco de muy importante de beneficios fiscales y de incentivos fiscales al mecenazgo para las fundaciones.

29 "Son fundaciones las organizaciones constituidas sin fin de lucro que, por voluntad de sus creadores, tienen afectado de modo duradero su patrimonio a la realización de fines de interés general" (artículo 2.1 Ley 50/2002, de 26 de diciembre de Fundaciones). En la escritura de constitución debe constar, necesariamente, "la dotación, su valoración y la forma y realidad de su aportación” (artículo 10 c) Ley 50/2002). "La dotación, que podrá consistir en bienes o derechos de cualquier clase, ha de ser adecuada y suficiente para el cumplimiento de los fines fundacionales. Se presumirá suficiente la dotación cuyo valor económico alcance los 30.000 euros" (artículo 12.1 Ley 50/2002). La necesidad de dotación está presente lógicamente en todas las leyes autonómicas de fundaciones, si bien no siempre se regula en los mismos términos. Por ejemplo existen diferencias en lo que se refiere a la forma de aportar la dotación (desembolso inicial y aportaciones sucesivas) o respecto a su importe mínimo (en Cataluña se cifra en 60.000 euros, artículo 331-5 de la Ley 4/2008, de 24 de abril, del Libro Tercero del Código Civil de Cataluña, relativo a las personas jurídicas).

${ }^{30}$ El artículo 5.1 de la Ley Orgánica 1/2002, de 22 de marzo, reguladora del Derecho de Asociación establece que "Las asociaciones se constituyen mediante acuerdo de tres o más personas físicas o jurídicas legamente constituidas, que se comprometen a poner en común conocimientos, medios y actividadades para conseguir unas finalidades lícitas, comunes, de interés general o particular, y se dotan de los Estatutos que rigen el funcionamiento de la asociación”. Por ello, como señala Paniagua (2006, p. 168), en las asociaciones el patrimonio puede ser inexistente, como sucede con frecuencia, ya que las aportaciones iniciales pueden consistir en obligaciones de hacer y no hacer.
}

REVESCO No 110 - Primer Cuatrimestre 2013 - ISSN: 1885-8031 - www.ucm.es/info/revesco 
concerniente al número de sus miembros y a su perfil (supuesto que en las fundaciones cívicas deben tener siempre un carácter significativo respecto a la comunidad local), junto a la existencia de una estructura de gobierno claramente definida en la legislación en cuanto a sus competencias supremas (las atribuidas legalmente al patronato) y régimen de responsabilidades (de los patronos), contribuye a un proceso más claro, ágil, eficiente y eficaz para la toma de decisiones del que existe en los modelos asamblearios de las asociaciones. Esto que de por sí es siempre importante en una organización, cobra todavía más relevancia si la entidad desarrolla actividades económicas.

4. La misión abierta que caracteriza a este tipo de entidades lleva a que la concreción de los fines genéricos deba realizarse, en cada momento, por un patronato que refleja en su composición, por tratarse de una fundación cívica, a la comunidad diversa. Esta característica organizativa refuerza la implicación de los sujetos que participan o colaboran con la entidad, pues fomenta la pertinencia de las acciones (las más necesarias o urgentes en cada momento) en el marco de los fines tendencialmente abiertos de la fundación y, en alguna medida, la presencia y participación de la comunidad de referencia (a través de las personas significativas en el patronato).

5. El carácter significativo que debe concurrir en los miembros que componen el patronato, de tal forma que refleje suficientemente a la comunidad local, aporta una información y criterios de decisión plurales. Esto constituye una importante ventaja organizativa, pues enriquece las percepciones de la realidad y contribuye a ponderar de forma equilibrada las acciones a emprender, así como la evaluación de los resultados. De esta forma las decisiones tenderán a ser más "libres" (menos sesgadas hacia determinados puntos de vista predominantes) ya que, por un lado, las distintas percepciones y perspectivas pueden ampliar el horizonte y abanico de alternativas estratégicas sobre las que decidir, y, por otro, éstas tenderán a concretarse en decisiones fundamentadas en términos objetivos (racionales) ya que deberán estar suficientemente justificadas y razonadas para llegar a acuerdos en el órgano colegiado (el patronato).

6. Que la cultura organizativa y los procesos tengan que responder a dinámicas participativas y de cooperación, tanto hacia el interior de la entidad como en la colaboración con otras entidades, contribuye a lograr sinergias y a alinear esfuerzos y recursos diversos en la consecución de los fines de la entidad, a empoderar a otras entidades del Tercer Sector y a generar alianzas que coadyuvan a generar capital social y redes de gobernanza en el ámbito 
local.

\section{LAS FUNDACIONES CÍVICAS COMO SUPUESTO DE INNOVACIÓN SOCIAL ORGANIZATIVA}

Se entiende por innovación social las acciones que tienen como resultado la creación de soluciones novedosas que benefician al conjunto de la sociedad, contribuyendo a su desarrollo sostenible, sea en términos sociales o medioambientales (Chambon et al 1982; Mulgan et al 2007; Morales Gutiérrez, 2008, 2009, 2010, Jiménez y Morales, 2011).

La innovación social puede ser en nuevos productos, servicios o formas de actuar ${ }^{31}$. Pero la innovación también puede ser en nuevos modelos organizativos, es decir, en lo que se refiere a la forma de dotar a las organizaciones de una misión (fines), estructura o procesos más adecuados y pertinentes para afrontar y solucionar los nuevos problemas. En todo caso, para que la innovación pueda ser calificada de social, las mejoras en diseños organizativos, productos o procesos tienen que poder utilizarse por todos los actores que estén interesados en su uso o aplicación. Es decir, tienen que ser suceptibles de uso general y, en consecuencia, deben poder emplearse por cualquier grupo o entidad para resolver o afrontar problemas sociales, no estando por ello constreñido o restringido su uso (mediante patentes, propiedad intelectual, secreto industrial o comercial, deber de confidencialidad de empleados, etc.) a sus creadores o inventores (Jiménez y Morales, 2011, p. 42).

El original diseño de las fundaciones cívicas puede ser utilizado por cualquier grupo interesado en resolver las problemáticas que puedan afectar a su comunidad de referencia, por lo que nos encontremos ante un claro ejemplo de innovación social organizativa. El carácter abierto que presenta la innovación social, a diferencia de lo que ocurre en muchas ocasiones en la innovación empresarial, permite aplicar los modelos exitosos a otros lugares o contextos diferentes a aquellos en los que surgió el fenómeno innovador. Esto es lo que está intentado hacer la Fundación Ferrer, con grandes logros en la India a través de diversos modelos de lucha contra la pobreza y exclusión social, en otros lugares del planeta. Eso mismo es lo que, con el objetivo de potenciar el compromiso ciudadano, está tratando de realizar la Fundación Bertelsman en Alemania y en España con respecto al diseño organizativo de las fundaciones

\footnotetext{
${ }^{31}$ Phills et al. (2008) destacan que la innovación social puede ser un producto, proceso de producción o la propia tecnología, pero también puede ser un principio, una idea, una legislación novedosa, un movimiento social, una intervención o una combinación de ellos. De hecho, muchas de las más reconocidas innovaciones sociales, tales como las microfinanzas, son combinaciones de varios de estos elementos.
} 
cívicas $^{32}$, y en el caso de estas entidades lo que más sorprende de su proliferación "es que el modelo ha resultado ser excepcionalmente adaptable a las diversas culturas, así como a sus respectivos entornos sociales y políticos y sus tradiciones benéficas” (Carson, 2009, p.89).

\section{LA RECEPCIÓN DE LAS FUNDACIONES CÍVICAS EN EL DERECHO ESPAÑOL DE FUNDACIONES}

No existe en nuestro ordenamiento jurídico ningún tipo de procedimiento específico para calificar a una fundación como cívica ${ }^{33}$ que nos permita extraer ciertas consecuencias respecto a la visibilidad y reconocimiento, representación institucional, concesión de ayudas, régimen tributario de la entidad, incentivación fiscal al mecenazgo, etc. Tampoco es previsible que el reconocimiento legal tenga lugar en los próximos años, pues no está en la tradición jurídica del Derecho de fundaciones español el establecer clasificaciones de fundaciones. Salvo en lo que se refiere al criterio clasificatorio que tiene en cuenta los fines de la entidad (más utilizado y relevante en el pasado que en la actualidad) o el ámbito de actuación territorial (que determina la normativa aplicable) ${ }^{34}$, la legislación sustantiva de fundaciones no establece tipologías de fundaciones. Éstas son más bien fruto del trabajo doctrinal que categoriza y clasifica a las fundaciones a partir de sus principales características $^{35}$. Por otro lado, calificar jurídicamente a una fundación como cívica supondría un reto jurídico nada fácil de afrontar, ya que algunos de los caracteres de este tipo de fundaciones, que son precisamente los que les atribuyen una naturaleza híbrida, son demasiado etéreos, imprecisos e indeterminados y, por ello, de no fácil concreción en una norma jurídica de carácter general ${ }^{36}$.

Por todo lo apuntado a este tipo de fundaciones se les aplica, sin ningún tipo de particularidad, la legislación española de fundaciones. Esta normativa es muy diversa puesto

\footnotetext{
${ }^{32}$ Como ya hemos apuntado, con el objetivo de fomentar el compromiso de los ciudadanos, se creó en Alemania en 1996 la Bertelsmann Stiftung y en España en 2006 el Centro de Competencias para las Fundaciones Cívicas. En ambos casos se pretende fomentar la creación y desarrollo de este tipo de fundaciones pues constituye un diseño organizativo muy apropiado para el desarrollo del compromiso ciudadano.

${ }^{33}$ De momento, tal y como hemos señalado, sólo existe una calificación social (el sello de fundación cívica), no jurídica, que viene realizando la Fundación Bertelsmann a través de su Centro de Competencias para Fundaciones cívicas tras analizar si en la entidad concurren los requisitos propios de las fundaciones cívicas.

${ }^{34}$ Ambos son criterios relativamente objetivos, pues tanto los fines como el ámbito de actuación deben constar expresamente en los estatutos.

${ }_{35}$ Por ejemplo, doctrinalmente se suele distinguir entre fundaciones patrimoniales o no patrimoniales; entre fundaciones de empresa, con empresa o fundaciones empresa, etc.

${ }^{36}$ ¿Qué debería entenderse por personas o entidades significativas en la comunidad local a los efectos de ser miembros del patronato?, ¿cómo se concretaría la importancia que habría que conceder, de cara a la calificación jurídica de fundación cívica, a la función de ayuda a otras entidades no lucrativas o a las actividades de liderazgo comunitario?, ¿cómo se concretaría jurídicamente la necesidad de procesos participativos y colaborativos?, etc.
} 
que estas fundaciones, como consecuencia de que su ámbito de actuación territorial suele ser local (un municipio, una provincia, una región, etc.), se regirán normalmente por alguna de las numerosas leyes de fundaciones que han ido aprobando las distintas comunidades autónomas $^{37}$. Atendiendo al ámbito territorial de aplicación de esta profusa legislación, sólo a aquellas fundaciones que operen principalmente en el territorio de una comunidad autónoma que no haya aprobado una ley de fundaciones, o a aquellas fundaciones "que desarrollen su actividad en todo el territorio del Estado, o principalmente en el territorio de más de una comunidad autónoma” ${ }^{38}$, les será aplicable la Ley de fundaciones estatal (Ley 50/2002, de Fundaciones). Es de gran importancia, en consecuencia, delimitar adecuadamente el ámbito de actuación territorial de la fundación, pues determina el marco normativo aplicable. Esto puede resultar en ocasiones complejo, especialmente cuando la entidad opere en zonas o comarcas limítrofes o pertenecientes a varias comunidades autónomas. Resulta indudable que esta dispersión normativa introduce una cierta complejidad a la hora de concretar la legislación aplicable (estatal o autonómica) a algunas fundaciones cívicas ${ }^{39}$, sobre todo cuando el legislador utiliza conceptos jurídicos indeterminados como ocurre con la expresión "principalmente en el territorio de más de una comunidad autónoma"40.

Por otro lado, es importante destacar que los fenómenos sociales que presentan un carácter híbrido no suelen ser de fácil regulación, pues el legislador normalmente parte de categorías jurídicas que presentan perfiles relativamente nítidos o típicos y que, por lo general, cuentan con un cierto recorrido histórico (categorías históricas). Por ello el carácter híbrido de las fundaciones cívicas comportará con toda probabilidad que algunas de sus características singulares no estén suficientemente consideradas en la normativa actual, lo que

\footnotetext{
${ }^{37}$ Actualmente existen las siguientes leyes de fundaciones autonómicas: Ley del Parlamento Vasco 12/1994, de 17 de junio de 1994, de Fundaciones; Ley 1/1998, de 2 de marzo, de Fundaciones de la Comunidad de Madrid; Ley 2/1998, de 6 de abril, de Fundaciones Canarias; Ley 8/1998, de 9 de diciembre, de Fundaciones de la Comunidad Valencia; Ley 13/2002, de 15 de julio, de Fundaciones de Castilla y León (Modificada por la Ley 12/2003 y por la Ley 2/2006); Ley 10-2005, de 31 de mayo, de Fundaciones de la Comunidad Autónoma de Andalucía; Ley 12/2006, de 1 de diciembre, de fundaciones de interés gallego; Ley 1/2007, de 12 de febrero, de Fundaciones de la Comunidad Autónoma de La Rioja; Ley 4/2008, de 24 de abril, del Libro Tercero del Código Civil de Cataluña, relativo a las personas jurídicas .

${ }^{38}$ Artículo 36.1 de la Ley 50/2002, y artículo 2.1. a) del Real Decreto 1337/2005, de 11 de noviembre, por el que se aprueba el Reglamento de fundaciones de competencia estatal.

${ }^{39}$ Lo mismo acontece con respecto a la legislación de otras personas jurídicas integrantes de la Economía Social, como ocurre con las cooperativas. Un magnífico análisis de esta cuestión puede verse en Paniagua Zurera (2005, pp. 58-63).

${ }^{40}$ También la Ley 27/1999, de 26 de julio, de Cooperativas, recurre a expresiones de este tipo: La presente Ley será de aplicación "A las sociedades cooperativas que desarrollen su actividad en el territorio de varias Comunidades autonómicas, excepto cuando en una de ellas se desarrolle con carácter principal" y "A las sociedades cooperativas que realicen principalmente su actividad cooperativizada en las ciudades de Ceuta y Melilla” (artículo 2).
} 
generará ciertas disfuncionalidades. Ejemplos de desajustes normativos los encontramos en el artículo 3.1 de la Ley 49/2002, de régimen fiscal de las entidades sin fines lucrativos y de los incentivos fiscales al mecenazgo y en el artículo 3.1 de la Ley 50/2002, de Fundaciones.

El artículo 3.1 de la Ley 49/2002 establece uno de los requisitos que tienen que cumplir las entidades sin fines lucrativos para que se les apliquen los beneficios fiscales y los incentivos fiscales al mecenazgo regulados en dicha Ley ${ }^{41}$. Es un precepto que por su redacción puede plantear problemas cuando las fundaciones cívicas conceden importantes ayudas económicas a otras entidades no lucrativas. De hecho la Dirección General de Tributos interpreta que si una fundación concede ayudas económicas muy significativas y relevantes a otras entidades no lucrativas se podría poner en duda si la entidad cumple con el requisito de perseguir fines de interés general. Esto es así porque esta Dirección general del Ministerio de Hacienda considera que el requisito establecido en el apartado $1^{\circ}$ del artículo 3 de la Ley 49/2002 “exige que sea la propia fundación directamente la que persiga fines de interés general, sin que pueda entenderse cumplido este requisito por el hecho de destinar los ingresos a otras fundaciones" ${ }^{42}$. Dada la importancia que para las fundaciones tiene la aplicación del régimen fiscal y de incentivación fiscal al mecenazgo de la Ley 49/2002, esta interpretación que puede derivarse de la redacción de su artículo 3.1 supone un obstáculo muy importante para la implantación y desarrollo de fundaciones cívicas con una importante función donante. A este hecho hay que añadir que el artículo 3.1 de la Ley 49/2002 tiene prácticamente la misma redacción que el artículo 3.1 de la Ley 50/2002, de Fundaciones ${ }^{43}$, por lo que no es descabellado pensar que también puedan darse interpretaciones de este tipo

\footnotetext{
${ }^{41}$ Este requisito está regulado en los siguientes términos: “1 ${ }^{o}$. Que persigan fines de interés general, como pueden ser, entre otros, los de defensa de los derechos humanos, de las víctimas del terrorismo y actos violentos, los de asistencia social e inclusión social, cívicos, educativos, culturales, científicos, deportivos, sanitarios, laborales, de fortalecimiento institucional, de cooperación para el desarrollo, de promoción del voluntariado, de promoción de la acción social, de defensa del medio ambiente, de promoción y atención a las personas en riesgo de exclusión por razones físicas, económicas o culturales, de promoción de los valores constitucionales y defensa de los principios democráticos, de fomento de la tolerancia, de fomento de la economía social, de desarrollo de la sociedad de la información, o de investigación científica y desarrollo tecnológico”.

${ }^{42}$ Consultas vinculantes V0618-05, V0062-06, V2282-06.

${ }^{43}$ El tenor literal del artículo 3.1 de la Ley 50/2002 es el siguiente: "Las fundaciones deberán perseguir fines de interés general, como pueden ser, entre otros, los de defensa de los derechos humanos, de las víctimas del terrorismo y actos violentos, asistencia social e inclusión social, cívicos, educativos, culturales, científicos, deportivos, sanitarios, laborales, de fortalecimiento institucional, de cooperación para el desarrollo, de promoción del voluntariado, de promoción de la acción social, de defensa del medio ambiente, y de fomento de la economía social, de promoción y atención a las personas en riesgo de exclusión por razones físicas, sociales o culturales, de promoción de los valores constitucionales y defensa de los principios democráticos, de fomento de la tolerancia, de desarrollo de la sociedad de la información, o de investigación científica y desarrollo tecnológico." Este artículo, según establece el número $1^{\circ}$ de la disposición final primera de la Ley 50/2002, constituye una de las condiciones básicas para "el ejercicio del derecho de fundación reconocido en el artículo 34, en relación con el 53, de la Constitución”, y es "de aplicación general al amparo de lo previsto en el artículo 149.1.1.a de la Constitución”.
} 
en el ámbito jurídico-sustantivo, lo que impediría la existencia de fundaciones cívicas en las que su función de ayuda económica a las actividades de otras entidades no lucrativas sean muy importantes y significativas.

Para resolver problemas como el descrito serán precisas normas específicas que adecuen o ajusten la normativa a los rasgos específicos de estas entidades ${ }^{44}$, no con el objeto de calificar como cívicas a las fundaciones, sino para que las aportaciones organizativas más significativas de estas entidades no se vean limitadas en su potencialidad y en su implementación práctica. Una reforma legislativa con respecto al problema que hemos apuntado podría ser que en el artículo 3.1 de la Ley 49/2002 y en el artículo 3.1 de la Ley 50/2002 se aclarase expresamente que las entidades sin fines lucrativos realizan también actividades de interés general cuando financian los proyectos de otras entidades no lucrativas que desarrollen actividades que están en consonancia con los fines de interés general de la entidad financiadora (la fundación cívica en este caso). A raíz de lo expuesto, se aprecia la importancia que tiene, para contar con una legislación adecuada, identificar las principales singularidades de las fundaciones cívicas, pues son de estas particularidades de las que derivan las principales aportaciones y ventajas organizativas de estas entidades.

\section{CONCLUSIONES}

Fines abiertos a lo que necesite una comunidad local determinada en cada momento; recursos diversos pero canalizados, coordinados y articulados de forma participativa, transparente y cooperativa desde dicha comunidad; mecanismos de gobierno independientes, plurales, nítidos y significativos son algunas de las singularidades que poseen las fundaciones cívicas dentro del elenco de las entidades del Tercer Sector.

\footnotetext{
${ }^{44}$ Así se hace por ejemplo, con respecto a las entidades que realizan cierto tipo de actividades, en el artículo $3.4^{\circ}$ de la Ley 49/2002, de régimen fiscal de las entidades sin fines lucrativos. Este precepto, que establece uno de los requisitos que deben cumplir las entidades sin fines lucrativos para que les resulte aplicable dicha la Ley, dispone que los asociados, fundadores, representantes estatutarios, patronos, miembros de los órganos de gobierno y parientes hasta el cuarto grado inclusive de cualquiera de ellos no pueden ser los principales destinatarios de las actividades de la entidad, ni beneficiarse de condiciones especiales para utilizar sus servicios. Se trata de una previsión lógica si nos encontramos ante entidades que gozan de beneficios fiscales por realizar actividades de interés general. Sin embargo, el legislador es consciente de que la aplicación de este requisito a las entidades que realizan cierto tipo de actividades supondría, por diversas razones, un freno importante para el desarrollo de dichas actividades. Esta es la razón por la que este requisito no resulta exigible con respecto a las actividades de investigación científica y desarrollo tecnológico, ni en relación con las actividades de asistencia social o deportivas a las que se refiere el artículo 20, apartado uno, en sus números $8^{\circ}$ y $13^{\circ}$, respectivamente, de la Ley del IVA, ni tampoco para las fundaciones cuya finalidad sea la conservación y restauración del Patrimonio Histórico Español que cumplan las exigencias de la Ley 16/1985, de 25 de junio, del Patrimonio Histórico Español, o de la Ley de la respectiva comunidad autónoma que le sea de aplicación, en particular respecto de los deberes de visita y exposición pública de dichos bienes.
} 
Estos rasgos idiosincráticos configuran un diseño organizativo propio y específico (la referida innovación social organizativa), en el que confluyen caracteres propios de las fundaciones tradicionales, pero también de los modelos asociativos. Esto comporta una organización que presenta unos perfiles organizativos híbridos y que posibilita una serie de ventajas que no aparecen de forma concurrente en los modelos asociativos ni en las fundaciones tradicionales.

La naturaleza fundacional clarifica indudablemente el carácter de los fines (de interés general), y aporta a la entidad una estructura patrimonial básica desde su nacimiento (la dotación) y una estructura de gobierno (representada por el patronato) que facilita los procesos de toma de decisiones que corresponden a la función de gobierno (la estrategia, el desarrollo organizativo, el control financiero y patrimonial, el nombramiento de los principales liderazgos, etc.) al hacerlos más nítidos (por estar claramente definido el órgano supremo de gobierno -el patronato-), más ágiles (al poder ser un órgano de composición limitada en cuanto al número de miembros), más eficientes y más eficaces.

Por otro lado, tener unos fines tendencialmente abiertos (misión abierta), que se pretenden cumplir mediante las decisiones de estrategia y de acción de un patronato que refleja a la comunidad de referencia (base social), y contar con una cultura organizativa y unos procesos participativos y cooperativos, aproxima a estas fundaciones a los modelos asociativos. Todos estos caracteres contribuyen a reforzar la implicación de los sujetos que participan o colaboran en la entidad, a priorizar los objetivos en función de lo que resulta más necesario o urgente en cada momento para esa comunidad de referencia, a que se pueda contar con una información más diversa y con unos criterios de decisión más ricos y plurales, coadyuva también a facilitar las sinergias y el alineamiento de esfuerzos y recursos para la consecución de los fines de la entidad, y a generar alianzas y colaboraciones con otras entidades lo que facilita la generación de capital social y de redes de gobernanza en el ámbito local, desde un barrio a una comarca o una provincia.

El Derecho de fundaciones español no establece una regulación propia para estas fundaciones. No las considera un tipo específico o singular de fundación de cuya calificación puedan derivarse ciertas consecuencias jurídicas (como ocurre, por ejemplo, respecto a la calificación de utilidad pública, en el caso de las asociaciones, o con las cooperativas sin ánimo de lucro o de iniciativa social, en el de las cooperativas). Por ello a este tipo de entidades les resulta de aplicación el marco normativo general de las fundaciones, que 
frecuentemente será, dado el ámbito de actuación local de estas entidades, el correspondiente a la comunidad autónoma en el que desarrolla la fundación su actividad, si bien en algunos casos podría ser el correspondiente a la legislación estatal. Dado el perfil organizativo híbrido propio de estas entidades es posible aventurar que la legislación de fundaciones, sustantiva y fiscal, presentará algunos desajustes al ser aplicado a estas entidades, lo que originará probablemente algunas disfuncionalidades que el legislador deberá evitar adoptando las correspondientes medidas legislativas.

En cualquier caso parece que la actual falta de implantación en España de este tipo de fundaciones obedece, más que a posibles desajustes normativos, al desconocimiento de su existencia y de las ventajas que derivan de su diseño organizativo. Ante la necesidad creciente de articular una ciudadanía que se comprometa más en los asuntos que afectan al conjunto de la comunidad mediante el establecimiento de sistemas de gobernanza de lo social, y dadas las ventajas organizativas que presentan las fundaciones cívicas, existe un evidente potencial de desarrollo de este tipo de instituciones en la realidad española, máxime si se considera tanto lo que ha sucedido -y está ocurriendo- en otros países del mundo, como las experiencias ya existentes en el territorio español. Por ello este estudio ha intentado poner de manifiesto la virtualidad de este diseño organizativo para potenciar y articular una ciudadanía que sea capaz de hacer frente a los problemas que pueden ir planteándose en sus comunidades de referencia. En todo caso, corresponde a la sociedad y a los poderes públicos valorar y decidir sobre la generación de los mecanismos institucionales más adecuados para comprometerse y responder a los desafíos de un mundo que, siendo global, tiene unas necesidades locales e idiosincráticas ineludibles.

\section{BIBLIOGRAFIA}

CABRA DE LUNA, M. A. (1998): El Tercer Sector y las fundaciones de España hacia el nuevo milenio. Enfoque económico, sociológico y jurídico. Madrid: Ed. Escuela Libre Editorial.

CHAMBON, J. L., DAVID, A., DEVEVEY, J. M. (1982): Les Innovations Sociales. París : Presses Universitaires de France.

CARSON, E.D. (2009): "El mito de la neutralidad de las fundaciones cívicas: el compromiso con la justicia social", en deCOURCY HERO, P. y WALKENHORST, P. (Eds.), Las fundaciones cívicas en el siglo XXI. Misión local, visión global. Barcelona: Fundación Bertelsmann, p. 89-101. 
DE COURCY HERO, P. y WALKENHORST, P. (2009): "Las fundaciones cívicas y la globalización de la filantropía. Introducción", en deCOURCY HERO, P. y WALKENHORST, P. (Eds.), Las fundaciones cívicas en el siglo XXI. Misión local, visión global. Barcelona: Fundación Bertelsmann, p. 19-25.

HERRERA GÓMEZ, J. (1998): "La especificidad organizativa del Tercer Sector: tipos y dinámicas”. Papers. Revista de Sociología, no 56, p.163-196.

JEANTET, T. (2006): Économie Sociale: la solidarité au défi de l'efficacité. Ed: La Documentation française.

JIMÉNEZ ESCOBAR, J. (2006): "El régimen tributario de las entidades sin fines lucrativos y de los incentivos fiscales al mecenazgo", en JIMÉNEZ ESCOBAR, J. y MORALES GUTIÉRREZ, A.C. (Directores), Dirección de entidades no lucrativas. Marco Jurídico, análisis estratégico y gestión. Cizur Menor (Navarra): Thomson Civitas, p. 181-216.

JIMÉNEZ ESCOBAR, J. (2006): "La fiscalidad de las fundaciones: un equilibrio entre la promoción del Estado social y la competencia en los mercados”. CIRIEC. Revista de Economía Pública, Social y Cooperativa, nº 56, p. 225-262.

JIMÉNEZ ESCOBAR, J. y MORALES GUTIÉRREZ, A.C. (2006): "Las entidades no lucrativas: concepto, caracteres y especificidad en la gestión", en JIMÉNEZ ESCOBAR, J. y MORALES GUTIÉRREZ, A.C. (Directores), Dirección de entidades no lucrativas. Marco Jurídico, análisis estratégico y gestión. Cizur Menor (Navarra): Thomson Civitas, p. $87-135$.

JIMÉNEZ ESCOBAR, J. y MORALES GUTIÉRREZ, A. C. (2008): “Tercer Sector y univocidad conceptual: necesidad y elementos configuradores". Revista Katálysis, Vol.11, $n^{\circ} 1$, p. 84-95.

JIMÉNEZ ESCOBAR, J. y MORALES GUTIÉRREZ, A. C. (2011): “Social economy and the fourth sector, base and protagonist of social innovation". CIRIEC. Revista de Economía Pública, Social y Cooperativa, no 73, Special Issue, p. 33-60.

LEVITT, T.: (1973), The Third Sector-New Tactics for a Responsive Society. Nueva York: Ed. A Division of American Management Associations.

McINNES, B. (2009): "Normas para el compromiso: generar activos y asociarse con los donantes", en deCOURCY HERO, P. y WALKENHORST, P. (Eds.), Las fundaciones cívicas en el siglo XXI. Misión local, visión global. Barcelona: Fundación Bertelsmann, p. 105-124.

MOHN, B. (2006): "La gestión innovadora de las fundaciones como agente impulsor del 
cambio social", en HERTEL, M. y WITTEMBORG, A. (Coord.), Compromiso cívico. Barcelona: Fundación Bertelsmann, p. 92-94.

MONZÓN, J.L. (2006): "Economía Social y conceptos afines: fronteras borrosas y ambigüedades conceptuales del Tercer Sector”. CIRIEC. Revista de Economía Pública, Social y Cooperativa, $\mathrm{n}^{\circ}$ 56, p. 9-24.

MORALES GUTIÉRREZ, A. C. (2008): “Innovación social: un proceso emergente en las dinámicas de desarrollo". Revista de Fomento Social, nº 63, p. 411-444.

MORALES GUTIÉRREZ, A. C. (2009): "Innovación social y servicios sociales". Zerbitzuan. Revista de Servicios Sociales, Junio, nº 45, p.151-178.

MORALES GUTIÉRREZ, A. C. (2010): “Claves para comprender la innovación social”, en VV.AA. La innovación social como motor de Europa. Sevilla: Social Innova, p.13-40.

MULGAN, G., TUCKER, S., RUSHANARA, A., SANDERS, B. (2007): Social Innovation: what it is, why it matters and how it can be accelerated, The Young Foundation.

PANIAGUA ZURERA, M. (2005): "Las sociedades cooperativas. Las sociedades mutuas de seguros y las mutualidades de previsión social”, en G. JIMÉNEZ SÁNCHEZ (Coord.), Tratado de Derecho Mercantil, tomo XII, vol $1^{\circ}$. Madrid, Marcial Pons.

PANIAGUA ZURERA, M. (2006): "El régimen sustantivo de las asociaciones", en JIMÉNEZ ESCOBAR, J. y MORALES GUTIÉRREZ, A.C. (Directores), Dirección de entidades no lucrativas. Marco Jurídico, análisis estratégico y gestión. Cizur Menor (Navarra): Thomson Civitas, p. 137-180.

PANIAGUA ZURERA, M. (2011): Las empresas de la economía social. Más allá del comentario a la Ley 5/2011, de Economía Social. Madrid: Marcial Pons.

PHILLS, DEIGLMEIR, MILLER (2008): “Rediscovering social innovation”. Stanford Social Innovation Review.

SACKS, E. W. (2000): The Growts of Community Foundations Around the World. An examination of the vitally of the community foundation movement. Council on Foundations.

SÁNCHEZ de FRUTOS, R.G. (1965): “La asociación. Su régimen jurídico en derecho español”. Revista Crítica de Derecho Inmobiliario, n 446-447, p.883-902.

ST. JOHN, S. E. (2007): Análisis de la Fundació Tot Raval, Second Star Philanthropic Services, publicado en Compromiso de los ciudadanos con los ciudadanos. El caso de la Fundació Tot Raval. Fundación Bertelsmann (www.fundacionbertelsmann.org).

ST. JOHN, S. E. (2009): Estudio de la Fundación Maimona, Second Star Philanthropic Services, publicado en Compromiso de los ciudadanos con los ciudadanos. Estudio de la 
Fundación Maimona. Fundación Bertelsmann (www.fundacionbertelsmann.org).

ST. JOHN, S. E. (2009): Estudio de la Fundació Ciutat de Valls, Second Star Philanthropic Services, publicado en Compromiso de los ciudadanos con los ciudadanos. Estudio de la Fundació Ciutat de Valls. Fundación Bertelsmann (www.fundacionbertelsmann.org).

ST. JOHN, S. E. (2009): Estudio de la Fundación Novessendes, Second Star Philanthropic Services, publicado en Compromiso de los ciudadanos con los ciudadanos. Estudio de la Fundación Novessendes. Fundación Bertelsmann (www.fundacionbertelsmann.org).

VV.AA. (2011): Manual de gestión de fundaciones cívicas. Barcelona: Fundación Bertelsmann.

WALKENHORST, P. (2001): Building Philantropic and Social Capital. The Work of Community Foundations. Gütersloh: Bertelsmann Foundation Publishers. 